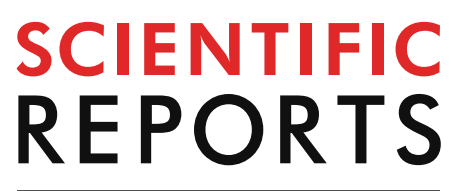

natureresearch

Check for updates

\title{
Obesity attenuates the effect of sleep apnea on active TGF-ß1 levels and tumor aggressiveness in patients with melanoma
}

\author{
Carolina Cubillos-Zapata ${ }^{1,2}$, Miguel Ángel Martínez-García ${ }^{2,3}$, Elena Díaz-García ${ }^{1,2}$, \\ Ana Jaureguizar ${ }^{1}$, Francisco Campos-Rodríguez ${ }^{2,4}$, Manuel Sánchez-de-la-Torre ${ }^{2,5}$, \\ Eduardo Nagore ${ }^{6}$, Antonio Martorell-Calatayud ${ }^{7}$, Luis Hernández Blasco ${ }^{8,9}$, Esther Pastor ${ }^{10}$, \\ Jorge Abad-Capa ${ }^{2,11}$, Josep María Montserrat ${ }^{2,12}$, Valentín Cabriada-Nuño ${ }^{13}$, \\ Irene Cano-Pumarega ${ }^{14}$, Jaime Corral-Peñafiel ${ }^{2,15}$, Eva Arias $^{16}$, Olga Mediano ${ }^{2,17}$, \\ María Somoza-González ${ }^{18}$, Joan Dalmau-Arias ${ }^{19}$, Isaac Almendros ${ }^{2,20,21}$, Ramón Farré2,20,21, \\ Eduardo López-Collazo ${ }^{2,22,23}$, David Gozal ${ }^{24}$ \& Francisco García-Río ${ }^{1,2,25 凶}$
}

Active transforming growth factor- $\beta 1$ (TGF- $\beta 1$ ), a cytokine partially regulated by hypoxia and obesity, has been related with poor prognosis in several tumors. We determine whether obstructive sleep apnea (OSA) increases serum levels of active TGF- $\beta 1$ in patients with cutaneous melanoma (CM), assess their relationship with melanoma aggressiveness and analyze the factors related to TGF- $\beta 1$ levels in obese and non-obese OSA patients. In a multicenter observational study, 290 patients with CM were underwent sleep studies. TGF- $\beta 1$ was increased in moderate-severe OSA patients vs. nonOSA or mild OSA patients with CM. In OSA patients, TGF- $\beta 1$ levels correlated with mitotic index, Breslow index and melanoma growth rate, and were increased in presence of ulceration or higher Clark levels. In CM patients, OSA was associated with higher TGF- $\beta 1$ levels and greater melanoma aggressiveness only in non-obese subjects. An in vitro model showed that $\mathrm{IH}$-induced increases of TGF- $\beta 1$ expression in melanoma cells is attenuated in the presence of high leptin levels. In conclusion, TGF- $\beta 1$ levels are associated with melanoma aggressiveness in CM patients and increased in

\footnotetext{
${ }^{1}$ Grupo de Enfermedades Respiratorias, Servicio de Neumología, Hospital Universitario La Paz-IdiPAZ, Paseo de La Castellana 261, 28046 Madrid, Spain. ${ }^{2}$ Centro de Investigación Biomédica en Red en Enfermedades Respiratorias (CIBERES), Madrid, Spain. ${ }^{3}$ Respiratory Department, Hospital Universitario y Politécnico La Fe, Valencia, Spain. ${ }^{4}$ Respiratory Department, Hospital Universitario de Valme, IBIS, Seville, Spain. ${ }^{5}$ Group of Precision Medicine in Chronic Diseases, Hospital Universitari Arnau de Vilanova and Santa Maria, IRBLleida, Lleida, Spain. ${ }^{6}$ Dermatology Department, Instituto Valenciano de Oncología, Valencia, Spain. ${ }^{7}$ Dermatology Department, Hospital de Manises, Valencia, Spain. ${ }^{8}$ Respiratory Department, ISABIAL, Hospital General Universitario de Alicante, Alicante, Spain. ${ }^{9}$ Departamento Medicina Clinica, Universidad Miguel Hernandez, Elche, Spain. ${ }^{10}$ Respiratory Department, Hospital San Juan de Alicante, Alicante, Spain. ${ }^{11}$ Respiratory Department, Centro de Investigacion Biomedica, Hospital Germans Trias i Pujol, Madrid, Spain. ${ }^{12}$ Respiratory Department, Hospital Clinic- IDIBAPS, Barcelona, Spain. ${ }^{13}$ Respiratory Department, Hospital Universitario Cruces, Bilbao, Spain. ${ }^{14}$ Respiratory Department, Hospital Universitario Ramón y Cajal, Madrid, Spain. ${ }^{15}$ Respiratory Department, Hospital Universitario S. Pedro Alcántara, Cáceres, Spain. ${ }^{16}$ Respiratory Department, Hospital 12 de Octubre, Madrid, Spain. ${ }^{17}$ Respiratory Department, Hospital Universitario de Guadalajara, Guadalajara, Spain. ${ }^{18}$ Pneumology Department, Hospital Consorcio Terrassa, Barcelona, Spain. ${ }^{19}$ Dermatology Department, Hospital de la Santa Creu i Sant Pau, Barcelona, Spain. ${ }^{20}$ Unitat de Biofísica I Bioenginyeria, Facultat de Medicina i Ciències de la Salut, Universitat de Barcelona, Barcelona, Spain. ${ }^{21}$ Institut d'Investigacions Biomèdiques August $\mathrm{Pi}$ i Sunyer (IDIBAPS), Barcelona, Spain. ${ }^{22}$ Tumorlmmunology Laboratory IdiPAZ, Madrid, Spain. ${ }^{23}$ Innate Immune Response Group, IdiPAZ, Madrid, Spain. ${ }^{24}$ Department of Child Health, University of Missouri School of Medicine, Columbia, MO, USA. ${ }^{25}$ Facultad de Medicina, Universidad Autónoma de Madrid, Madrid, Spain. ${ }^{\varpi}$ email: fgr01m@ gmail.com
} 
moderate-severe OSA. Moreover, in non-obese patients with OSA, TGF- $\beta 1$ levels correlate with OSA severity and leptin levels, whereas only associate with leptin levels in obese OSA patients.

The putative association between obstructive sleep apnea (OSA) and cutaneous melanoma (CM) aggressiveness ${ }^{1,2}$, a malignant tumor which despite substantial progress in therapy retains high mortality rates, has been reinforced by improved identification of biologically plausible pathophysiological pathways. OSA effects on tumor development and progression have been mainly attributed to the impact of intermittent hypoxia on the local tumor microenvironment, promoting melanoma cell proliferation, the release of pro-angiogenic factors, and alterations of the immune surveillance system ${ }^{1,3-5}$. However, the impact of OSA on the intrinsic properties of tumor cells is less well understood.

There is increasing evidence that the aggressiveness of CM is largely due to the intrinsic plasticity of melanoma cells, which is regulated by a variety of mechanisms that prominently include the transforming growth factor- $\beta$ (TGF- $\beta$ ) pathway ${ }^{6,7}$. TGF- $\beta$ is a multi-factorial peptide growth factor that is synthesized by macrophages, lymphocytes, fibroblasts, platelets, epithelial and cancer cells, and plays a key role in the regulation of several physiological processes, including cell proliferation, differentiation, migration, adhesion, and tissue repair ${ }^{8}$. TGF- $\beta$ synthesized forms a dimer of with a latency-associated peptide, remaining inactive and anchored in the extracellular matrix by the TGF- $\beta$ binding proteins. TGF- $\beta$ activation requires its release form the extracellular matrix by proteolytic cleavage ${ }^{9}$. To adequately evaluate serum TGF- $\beta$, it is important to consider that most of it corresponds to the latent complex form, while only a small fraction is biologically active ${ }^{10}$.

In melanoma cells, extracellular active TGF- $\beta$ regulates gene expression by receptor-mediated activation of SMAD (an acronym from the fusion of Caenorhabditis elegans Sma genes and the Drosophila Mad, Mothers against decapentaplegic) transcription factors that regulate the transcriptional output of active genes and can also open repressive chromatin ${ }^{7}$. Among the several TGF- $\beta$ isoforms, TGF- $\beta 1$ has been shown to be expressed by melanoma cells and to promote invasiveness in cell cultures ${ }^{11}$, whereas attenuation of TGF- $\beta$ signaling by treatment with a small molecule inhibitor reduced bone metastasis formation ${ }^{12}$. Although a previous study did not identify a relationship between serum TGF- $\beta 1$ concentration and melanoma stage ${ }^{13}$, probably because circulating bioactive TGF- $\beta 1$ levels were not specifically measured, it has been demonstrated that overall canonical TGF- $\beta$ /SMAD signaling is a potent promoter of melanoma progression, even at early stages of the disease ${ }^{14}$, and that soluble active TGF- $\beta 1$ is directly related to the risk of melanoma metastasis ${ }^{15,16}$.

The involvement of the TGF- $\beta$ /SMAD pathway in melanoma progression could be potentially important in OSA patients, since previous studies have shown that increased hypoxia-induced factor (HIF) secondary to hypoxia induces the activation of the TGF- $\beta 1 /$ SMAD signaling pathway ${ }^{17-19}$. Along the same line, it has been described that patients with severe OSA have higher circulating levels of active TGF- $\beta 1$ than control subjects, which decreases after six months of CPAP treatment ${ }^{20}$. Interestingly, it has also been reported that leptin synthesized and secreted by adipose tissues, after binding to its specific receptor on tumor cells, activates an intracellular signaling pathway that recruits transcription factors to the promoter of the TGF- $\beta 1$ gene, increasing synthesis and secretion of TGF- $\beta 1$ by tumor cells ${ }^{21}$.

Circulating TGF- $\beta 1$ levels have been shown to exhibit dependency on both intermittent hypoxia and obesity (mediated through serum leptin levels) $)^{19,21-23}$, and such observations lead to the question whether OSA may have any effect on the activation of the TGF- $\beta 1 /$ SMAD pathway in patients with melanoma, and if so, whether there is any synergistic effect with obesity. Therefore, our study objectives were to compare serum levels of active TGF- $\beta 1$ in patients with CM according to the presence and severity of OSA, assess the correlation between active TGF- $\beta 1$ levels and melanoma aggressiveness indices, and analyze their relationship with nocturnal hypoxia and serum levels of leptin in both obese and non-obese patients. Moreover, we explored the leptin effect on TGF- $\beta 1$ released by melanoma cells under intermittent hypoxia in an in vitro model of OSA.

\section{Results}

The general characteristics of the study participants are shown in Table 1 . We included 290 patients, 146 of which were men, with a median (IQR) age of 55 (44-69) years and a mean BMI of 27.0 (24.2-29.7) $\mathrm{Kg} \mathrm{m}^{-2}$. Local melanoma extension was detected in 250 patients (87\%), and evidence of ulceration was found in 49 (17\%). Median (IQR) Breslow and mitotic indices were $0.84(0.50-1.93) \mathrm{mm}$ and $1(0-2)$ cells $\mathrm{mm}^{-2}$, respectively; while the growth rate was $0.15(0.05-0.45) \mathrm{mm} \mathrm{month}^{-1}$. The overall prevalence rates of mild and moderate-to-severe OSA were 31.7 and $33.8 \%$, respectively. The comparison between groups illustrates that, as the severity of OSA increases, patients were increasingly more likely to be men, older and more obese.

Active TGF- $\beta 1$ is increased in moderate-severe OSA patients and correlates with melanoma aggressiveness. Active TGF- $\beta 1$ serum levels showed significant differences among the three study subgroups $(p<0.001)$. When adjusted for sex, age, BMI and neck circumference, TGF- $\beta 1$ serum levels were higher in moderate-severe OSA patients versus mild OSA or non-apneic patients (Fig. 1A).

In OSA patients, active TGF- $\beta 1$ levels exhibited a strong relationship with mitotic index $(r=0.405, p<0.001)$, Breslow index $(r=0.419, \mathrm{p}<0.001)$ and melanoma growth rate $(\mathrm{r}=0.309, \mathrm{p}<0.001)$ (Fig. 2). OSA patients with locoregional disease had higher TGF- $\beta 1$ levels than those with localized melanoma (9.64 [3.91-14.29] vs. 4.54 [2.35-9.04] $\left.\mathrm{pg} \mathrm{mL}^{-1}, \mathrm{p}=0.008\right)$. TGF- $\beta 1$ levels were also higher in OSA patients with ulceration of melanoma than in those without ulceration (9.07 [4.03-21.67] vs. 4.21 [2.09-8.75] $\left.\mathrm{pg} \mathrm{mL}^{-1}, \mathrm{p}=0.001\right)$. Finally, differences in TGF- $\beta 1$ levels according to Clark levels were also detected $(\mathrm{p}<0.001)$ (Fig. 2). 


\begin{tabular}{|c|c|c|c|c|}
\hline & Non OSA patients & Mild OSA patients & Moderate-severe OSA patients & $P$ \\
\hline $\mathrm{N}$ & 100 & 92 & 98 & - \\
\hline Males, n (\%) & $36(36)$ & $44(48)$ & $66(67)$ & $<0.001$ \\
\hline Age (years) & $41(36-49)$ & $57(44-73)$ & $68(59-76)$ & $<0.001$ \\
\hline BMI $\left(\mathrm{Kg} \mathrm{m}^{-2}\right)$ & $24.3(22.6-27.2)$ & $28.4(24.9-31.5)$ & $28.3(26.6-32.3)$ & $<0.001$ \\
\hline Neck circumference $(\mathrm{cm})$ & $36(33-39)$ & $37(35-39)$ & $40(37-43)$ & $<0.001$ \\
\hline Obesity, n (\%) & $7(7)$ & $27(29)$ & $37(38)$ & $<0.001$ \\
\hline Smoking status, $\mathbf{n}(\%)$ & & & & 0.456 \\
\hline Never & $47(47)$ & $51(55)$ & $50(51)$ & \\
\hline Current smoker & $23(23)$ & $15(16)$ & $14(14)$ & \\
\hline Past smoker & $30(30)$ & $26(28)$ & $34(35)$ & \\
\hline Type of melanoma, $\mathbf{n}(\%)$ & & & & 0.606 \\
\hline Superficial spreading melanoma & $76(76)$ & $67(73)$ & $62(64)$ & \\
\hline Lentigo maligna melanoma & $5(5)$ & $6(7)$ & $12(12)$ & \\
\hline Acral lentiginous melanoma & $4(4)$ & $5(5)$ & $5(5)$ & \\
\hline Nodular melanoma & $14(14)$ & $14(15)$ & $17(18)$ & \\
\hline Other & $1(1)$ & - & $1(1)$ & \\
\hline Mitotic index, $\left(\right.$ cells $\left.\mathrm{mm}^{-2}\right)$ & $1(0-2.5)$ & $1(0-3)$ & $1(0-5)$ & 0.055 \\
\hline Breslow index $(\mathrm{mm})$ & $0.75(0.51-1.38)$ & $0.80(0.51-2.20)$ & $1.20(0.70-3.00)$ & $<0.001$ \\
\hline Ulceration, n (\%) & $8(8)$ & $20(22)$ & $51(21)$ & 0.014 \\
\hline Growth rate, $\left(\mathrm{mm}\right.$ month $\left.^{-1}\right)$ & $0.11(0.06-0.34)$ & $0.14(0.06-0.27)$ & $0.38(0.08-0.89)$ & 0.005 \\
\hline Clark index & $3(2-3.5)$ & $3(2-4)$ & $3(3-4)$ & 0.004 \\
\hline Disease stage, $\mathbf{n}(\%)$ & & & & 0.048 \\
\hline Localized melanoma & $92(93)$ & $80(88)$ & $78(81)$ & \\
\hline Locoregional disease & $7(7)$ & $11(12)$ & $18(19)$ & \\
\hline ESS score & $7(3-9)$ & $6(4-7)$ & $6(4-9)$ & 0.353 \\
\hline AHI $\left(h^{-1}\right)$ & $2.0(0.7-2.9)$ & $8.6(6.8-11.2)$ & $29.8(21.6-46.0)$ & $<0.001$ \\
\hline ODI $\left(\mathrm{h}^{-1}\right)$ & $0.9(0.3-1.4)$ & $5.0(2.6-6.8)$ & $29.8(21.6-46.0)$ & $<0.001$ \\
\hline Mean nocturnal $\mathrm{SaO}_{2}(\%)$ & $94(93-96)$ & $93(92-95)$ & $93(92-94)$ & $<0.001$ \\
\hline Low nocturnal $\mathrm{SaO}_{2}(\%)$ & $89(86-91)$ & $81(78-88)$ & $79(75-85)$ & $<0.001$ \\
\hline $\mathrm{tSaO}_{2}<90 \%(\%)$ & $0.0(0.0-0.6)$ & $1.7(0.1-8.4)$ & $4.5(1.0-13.1)$ & $<0.001$ \\
\hline Leptin $\left(\mathrm{ng} \mathrm{mL} \mathrm{m}^{-1}\right)$ & $3.80(2.29-4.67)$ & $3.60(2.69-5.21)$ & $3.95(2.91-5.10)$ & 0.131 \\
\hline TGF- $\beta\left(\right.$ pg mL $\left.{ }^{-1}\right)$ & $3.91(2.08-7.59)$ & $3.71(0.98-9.44)$ & $4.78(2.09-11.42)$ & 0.001 \\
\hline
\end{tabular}

Table 1. General characteristics of the study subjects. Data are presented as median (interquartile range [IQR]) or n (\%) and significant differences are highlighted in bold. BMI body mass index; ESS Epworth sleepiness score; $A H I$ apnea-hypopnea index; ODI desaturation index; $\mathrm{SaO}_{2}$ oxygen saturation; $\mathrm{SaO}_{2}<90 \%$ night time spent with oxygen saturation $<90 \%$; TGF- $\beta 1$ tumor growth factor- $\beta 1$.

Leptin levels and OSA patient characteristics according to obesity. No significant differences in leptin levels were found among the melanoma patients without OSA and those with mild or moderate-severe OSA (Fig. 1B). In the OSA patients overall, leptin levels weakly correlated with melanoma growth rate $(\mathrm{r}=0.192$, $\mathrm{p}=0.008)$ and Breslow index $(\mathrm{r}=0.140, \mathrm{p}=0.054)$.

As would be anticipated, leptin levels were higher in obese than in non-obese OSA patients (4.49 [3.59-5.26] vs. 3.36 [2.38-4.68] $\mathrm{ng} \mathrm{mL} \mathrm{m}^{-1}, \mathrm{p}=0.001$ ), whereas active TGF- $\beta 1$ levels did not differ between subgroups of OSA patients (Table S1). In addition, among obese OSA patients there was a lower predominance of males as well as a greater severity of apneas-hypopneas and nocturnal hypoxemia when compared to nonobese OSA cases, but no significant differences in melanoma aggressiveness were identified.

TGF- $\beta 1$ levels only are related to OSA severity in non-obese patients. Table 2 shows the correlation between active TGF- $\beta 1$ levels, polygraphic parameters and leptin levels in OSA patients with or without obesity. In non-obese OSA patients, TGF- $\beta 1$ levels correlated with leptin levels as well as with AHI, desaturation index, lowest nocturnal oxygen saturation and time with $\mathrm{SpO}_{2}<90 \%$. In the multivariate stepwise regression model, AHI and leptin levels were retained as independent predictors of TGF- $\beta 1$ levels (Table 3, Fig. 3). In contrast, in obese patients with OSA, TGF- $\beta 1$ levels were only significantly related to leptin levels (Fig. 3). A sensitivity analysis using different BMI cut-off points (ranging from 28 to $33 \mathrm{~kg} \mathrm{~m}^{-2}$ ) showed similar results.

When all obese patients with CM were analyzed together, the presence of OSA was not associated with higher levels of TGF- $\beta 1$ or with greater tumor aggressiveness. In contrast, non-obese patients with OSA exhibited higher levels of TGF- $\beta 1$ and melanoma aggressiveness indices (Table S2). The correlation between serum levels 

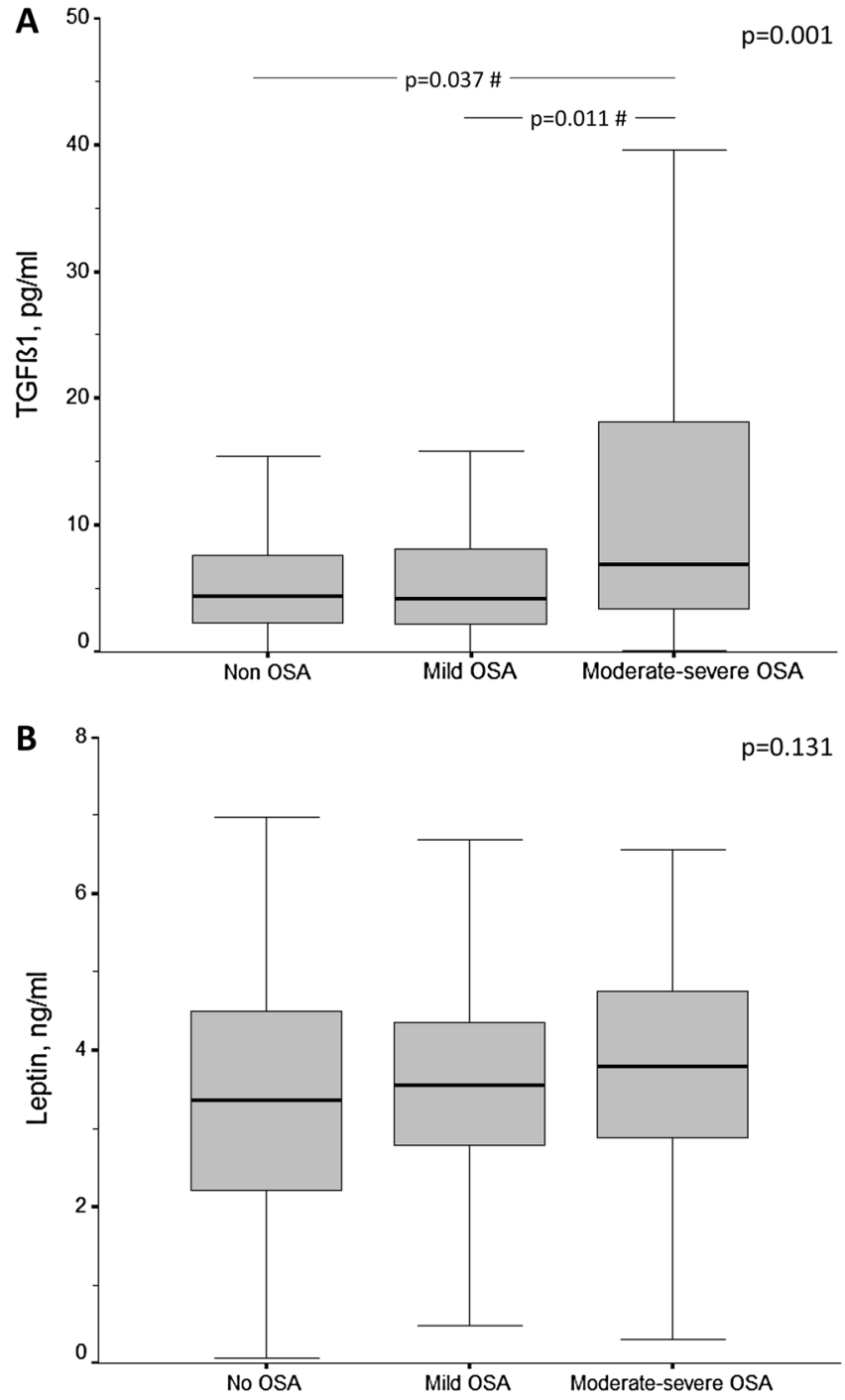

Figure 1. Box-and-whisker plots depicting the distribution of: (A) serum levels of active TGF- $\beta 1$; and (B) leptin, in cutaneous melanoma patients according to their apnea-hypopnea index. Data are presented as median (interquartile range), maximum and minimum values, and overall comparisons were performed using the Kruskal-Wallis test. ${ }^{*} p$-values corresponding to the post hoc comparisons between groups adjusted for sex, age, body mass index and neck circumference. OSA obstructive sleep apnea.

of active TGF- $\beta 1$ and melanoma aggressiveness indices was maintained after considering obese and non-obese OSA patients separately (Table S3).

In vitro effect of intermittent hypoxia on TGF- $\beta 1$ expression is modulated by leptin levels. IH exposures in vitro increased bioactive TGF- $\beta 1$ levels in the culture supernatant of melanoma cells subjected to the lowest leptin concentration, while such effect disappeared with the higher leptin concentration (Fig. 4). TGF- $\beta 1$ expression assessed by mRNA showed a similar trend, although it did not reach statistical significance (Fig. S1).

\section{Discussion}

In patients with cutaneous melanoma, moderate-severe OSA is associated with increased circulating levels of active TGF- $\beta 1$ which correlate with tumor aggressiveness. In addition, while TGF- $\beta 1$ levels are independently related to serum leptin and AHI in non-obese subjects, they associate with leptin levels only in obese subjects, suggesting that the potential contribution of OSA to increase active TGF- $\beta 1$ may be limited to non-obese patients. Moreover, the in vitro melanoma cell culture model showed that the IH-induced increase of active TGF- $\beta 1$ expression is attenuated by the presence of higher leptin levels.

The TGF- $\beta$ pathway plays a major role in the evolution of cancer, and has been implicated with tumor progression by driving epithelial mesenchymal transition, tumor cell migration, invasion, metastatic spread and angiogenesis $^{24}$. The roles of TGF- $\beta 1$ have been more extensively investigated relative to other isoforms of TGF- $\beta$. 

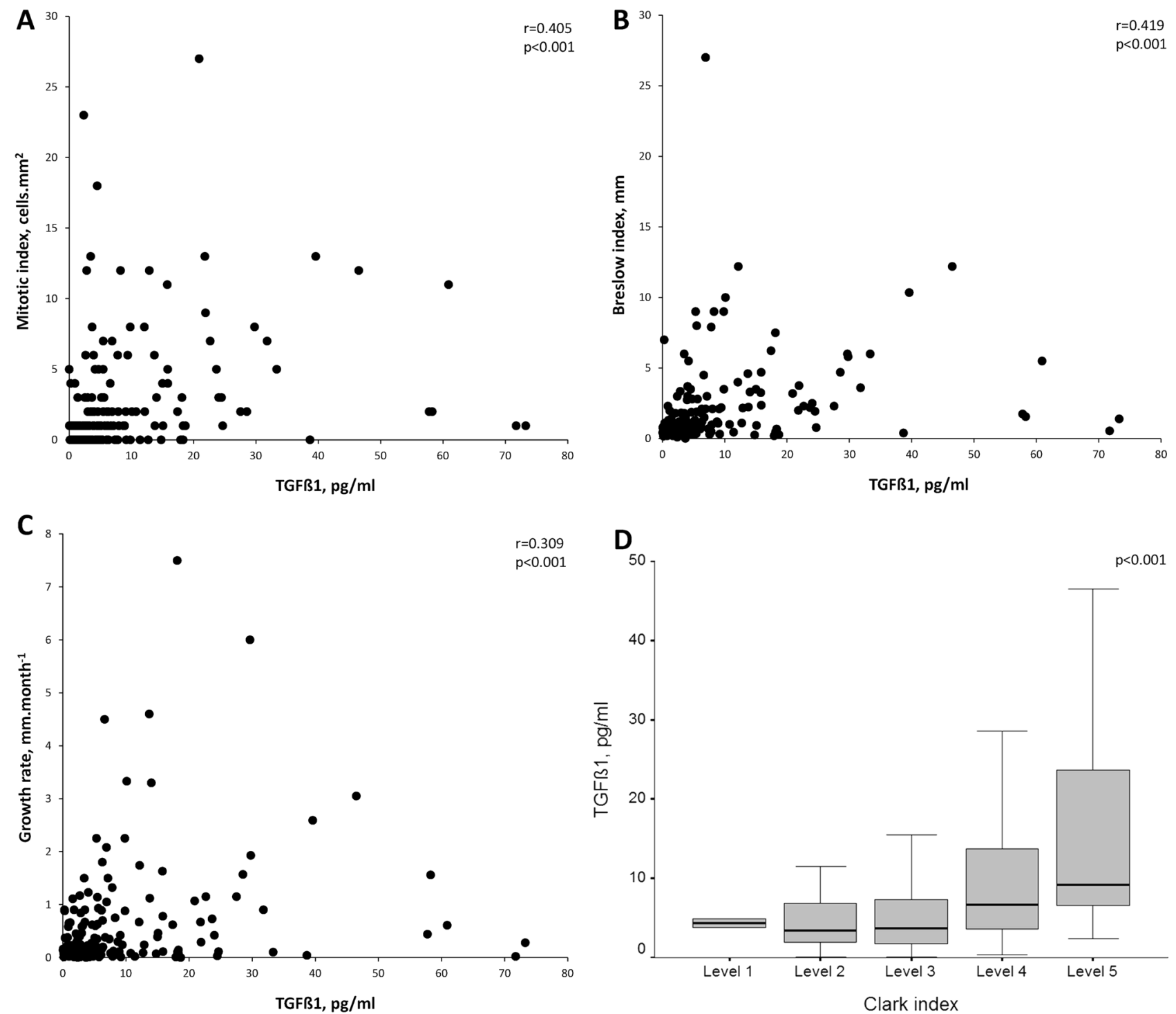

Figure 2. Relationship of serum levels of active TGF- $\beta 1$ with the mitotic index (A), Breslow index (B) and melanoma growth rate $(\mathbf{C})$ in patients with cutaneous melanoma and OSA. (D) Comparison of TGF- $\beta 1$ levels according Clark level in the OSA patients with cutaneous melanoma.

\begin{tabular}{|c|c|c|c|c|c|c|}
\hline & \multicolumn{3}{|c|}{ Non-obese OSA patients } & \multicolumn{3}{|c|}{ Obese OSA patients } \\
\hline & $\mathbf{r}$ & 95\%CI & $\mathbf{p}$ & $\mathbf{r}$ & 95\%CI & $\mathbf{p}$ \\
\hline Age (years) & 0.013 & -0.168 to 0.193 & 0.887 & 0.301 & \begin{tabular}{|l|}
0.053 to 0.514 \\
\end{tabular} & 0.018 \\
\hline BMI $\left(\mathrm{Kg} \mathrm{m}^{-2}\right)$ & 0.020 & -0.161 to 0.200 & 0.828 & -0.029 & -0.279 to 0.224 & 0.825 \\
\hline Neck circumference $(\mathrm{cm})$ & -0.055 & -0.233 to 0.127 & 0.555 & 0.203 & -0.051 to 0.433 & 0.116 \\
\hline ESS & -0.145 & -0.317 to 0.037 & 0.116 & 0.105 & -0.151 to 0.348 & 0.420 \\
\hline AHI $\left(\mathrm{h}^{-1}\right)$ & 0.241 & 0.063 to 0.404 & 0.008 & 0.225 & -0.028 to 0.451 & 0.081 \\
\hline DI $\left(h^{-1}\right)$ & 0.215 & \begin{tabular}{|l|}
0.036 \\
to 0.381
\end{tabular} & 0.025 & 0.059 & -0.196 to 0.306 & 0.651 \\
\hline Mean nocturnal $\mathrm{SpO}_{2}(\%)$ & -0.102 & -0.278 to 0.080 & 0.273 & -0.007 & -0.258 to 0.245 & 0.956 \\
\hline Low nocturnal $\mathrm{SpO}_{2}(\%)$ & -0.236 & -0.400 to -0.058 & 0.014 & -0.067 & -0.314 to 0.188 & 0.605 \\
\hline $\mathrm{tSpO}_{2}<90 \%(\%)$ & 0.208 & 0.028 to 0.375 & 0.045 & 0.085 & -0.170 to 0.330 & 0.512 \\
\hline Leptin serum levels $\left(\mathrm{ng} \mathrm{mL}^{-1}\right)$ & 0.206 & 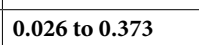 & 0.025 & 0.413 & 0.180 to 0.602 & 0.001 \\
\hline
\end{tabular}

Table 2. Anthropometric and sleep parameters related with active TGF- $\beta 1$ serum levels in the non-obese and obese OSA patients. BMI body mass index; ESS Epworth sleepiness score; $A H I$ apnea-hypopnea index; $D I$ desaturation index; $\mathrm{SpO}_{2}$ oxygen saturation; $t \mathrm{SpO}_{2}<90 \%$ night time spent with oxygen saturation $<90 \% ; r$ Spearman correlation coefficient; $C I$ confidence interval. 


\begin{tabular}{|c|c|c|c|c|c|c|c|c|}
\hline & \multicolumn{2}{|c|}{$\begin{array}{l}\text { Unstandardized } \\
\text { regression } \\
\text { coefficients }\end{array}$} & \multicolumn{2}{|l|}{$95 \%$ CI for B } & \multirow{2}{*}{\begin{tabular}{|l} 
Standardized regression \\
coefficients
\end{tabular}} & \multirow[b]{2}{*}{$P$ value } & \multirow[b]{2}{*}{$\mathbf{r}^{2}$} & \multirow[b]{2}{*}{$r^{2}$ change } \\
\hline & B & S.E & Lower limit & Upper limit & & & & \\
\hline \multicolumn{9}{|l|}{ Non obese OSA patients } \\
\hline Leptin level $\left(\mathrm{ng} \mathrm{mL} L^{-1}\right)$ & 2.180 & 0.717 & 0.760 & 3.601 & 0.269 & 0.001 & 0.091 & 0.091 \\
\hline AHI $\left(\mathrm{h}^{-1}\right)$ & 0.156 & 0.074 & 0.011 & 0.302 & 0.188 & 0.036 & 0.125 & 0.034 \\
\hline Constant & -1.737 & 2.862 & -7.406 & 3.931 & - & 0.545 & - & - \\
\hline \multicolumn{9}{|l|}{ Obese OSA patients } \\
\hline Leptin level $\left(\mathrm{ng} \mathrm{m}^{-1}\right)$ & 3.993 & 1.263 & 1.466 & 6.520 & 0.381 & 0.002 & 0.145 & 0.145 \\
\hline \begin{tabular}{|l|} 
Constant \\
\end{tabular} & -6.749 & 5.609 & -17.971 & 4.474 & - & 0.234 & - & \\
\hline
\end{tabular}

Table 3. Independent predictors of serum levels of active TGF- $\beta 1$ in obese and non-obese OSA patients with melanoma. AHI apnea-hypopnea index; S.E. standard error; CI confidence interval.

When bound to a specific receptor on the target cell membrane, TGF- $\beta 1$ activates TGF- $\beta$ receptor type I kinase, resulting in the phosphorylation of SMAD2 and SMAD3, which subsequently form oligomeric complexes with SMAD4, and translocate to the nucleus to regulate the expression of a large repertoire of genes ${ }^{21,25}$. In light of the biological roles of TGF- $\beta 1$ in cancer, the strong relationships between serum levels of active TGF- $\beta 1$ and all indices of melanoma aggressiveness in OSA patients are therefore not unexpected. The increased TGF- $\beta 1$ levels identified in patients with moderate-severe OSA indicate that this disorder has an incremental effect on the expression and release of active TGF- $\beta 1$ even in patients who have already developed a melanoma. Currently available evidence suggests that this effect is likely due to the OSA-related intermittent hypoxia. In fact, TGF- $\beta 1$ has been shown to be increased in a variety of cells cultured in hypoxia and also in hypoxic ischemic tissues ${ }^{26}$. Several reports show that hypoxia activates latent TGF- $\beta 1$ via HIF-1 $\alpha$ in hepatocytes, placental fibroblasts, primary human lung fibroblasts, smooth muscle cells and cancer cells ${ }^{22,26}$. Using in vitro models, it has been recently confirmed that HIF- $1 \alpha$ induction by hypoxia promotes the expression of TGF- $\beta 1$, activates its receptors, and increases the phosphorylation of the SMAD2/3 proteins, indicating an activation of the TGF- $\beta / S M A D$ signaling pathway, probably through the TLR/MyD88/NF-kB pathway ${ }^{23}$.

Although our results do not establish causal inferential mechanisms, the correlation found between the different nocturnal hypoxemia indices and the levels of active TGF- $\beta 1$ among patients with OSA and melanoma concurs with the potential relevance of intermittent hypoxia in the enhanced induction of TGF- $\beta 1$. The selection of AHI instead of the nocturnal hypoxemia indices by the multiple regression model could be due solely to the limited number of patients with more severe OSA (cutaneous melanoma was the driving selection criterion rather than OSA). However, it is also not possible to exclude that other OSA-related perturbations contribute to TGF- $\beta 1$ production. Indeed, in a murine model exposed to intense sleep fragmentation, increases in TGF- $\beta 1$ expression in the hypothalamus and hippocampus were reported ${ }^{27}$.

Leptin is primarily produced by fat cells and regulates food intake, energy homeostasis and cell proliferation ${ }^{28}$. High serum levels of leptin, which are strongly correlated with adipose tissue mass, are recognized as a factor driving cancer development and progression, as leptin exhibits mitogenic, proinflammatory, anti-apoptotic, and proangiogenic properties ${ }^{28-31}$. The finding of a significant relationship between leptin and TGF- $\beta 1$ levels in our patients is consistent with previous studies that showed that leptin binds to leptin receptors on the surface of cancer cells, activates JAK/STAT3 signaling, and consequently increases TGF- $\beta$ expression ${ }^{21}$. Moreover, it has been demonstrated that leptin can be a co-factor for TGF- $\beta$ in cancer using an in vitro model of kidney fibroblasts whereby leptin treatment enhances SMAD2/3 phosphorylation by TGF- $\beta^{32,33}$. Interestingly, the relationship between leptin and TGF $\beta$ could be bidirectional, since TGF $\beta /$ SMAD3 signaling appears to be crucial for the development of obesity, as demonstrated in mice in which TGF $\beta$ signaling was blocked or that were deficient in SMAD3 and consequently were protected from developing obesity ${ }^{34,35}$. Additionally, other members of the TGF- $\beta$ family are involved in regulation of adipogenesis and energy metabolism through SMAD and P38 signaling pathways ${ }^{36}$.

There is substantial evidence on the association between obesity and increased cancer risk and metastasi ${ }^{37}$. It has been estimated that roughly $20 \%$ of all cancers are caused by excess weight gain ${ }^{38,39}$ and, although the mechanisms are unclear, some studies have suggested that obesity enhances metastases in tumors such as melanoma, colon, lung and breast cancer ${ }^{40,41}$. In fact, there is greater risk of recurrence among cancer patients with higher $\mathrm{BMI}^{42}$, and cancer patients with high BMI have higher mortality rates compared to those with average $\mathrm{BMI}^{38}$. Although in our subgroup of patients with OSA and melanoma the differences in Breslow index between obese and non-obese subjects did not reach statistical significance (Table S1) (probably due to sample size), in the overall cohort, those who were obese had a higher Breslow index compared to non-obese $(1.10$ [0.60-2.15] vs. $0.80[0.47-1.70] \mathrm{mm}, \mathrm{p}=0.015)$, further reinforcing the observation that obesity is associated with greater melanoma aggressiveness.

The most striking finding in the present study is that the correlation between AHI and nocturnal hypoxemia indices with the serum levels of active TGF- $\beta 1$ among OSA patients reached statistical significance only in nonobese subjects, while in the obese the serum leptin concentration was the only independent variable associated with TGF- $\beta 1$ levels. Moreover, the results of our in vitro model confirmed that intermittent hypoxia-induced elevations in active TGF- $\beta 1$ expression in melanoma cells are attenuated by higher leptin levels. In this context, 

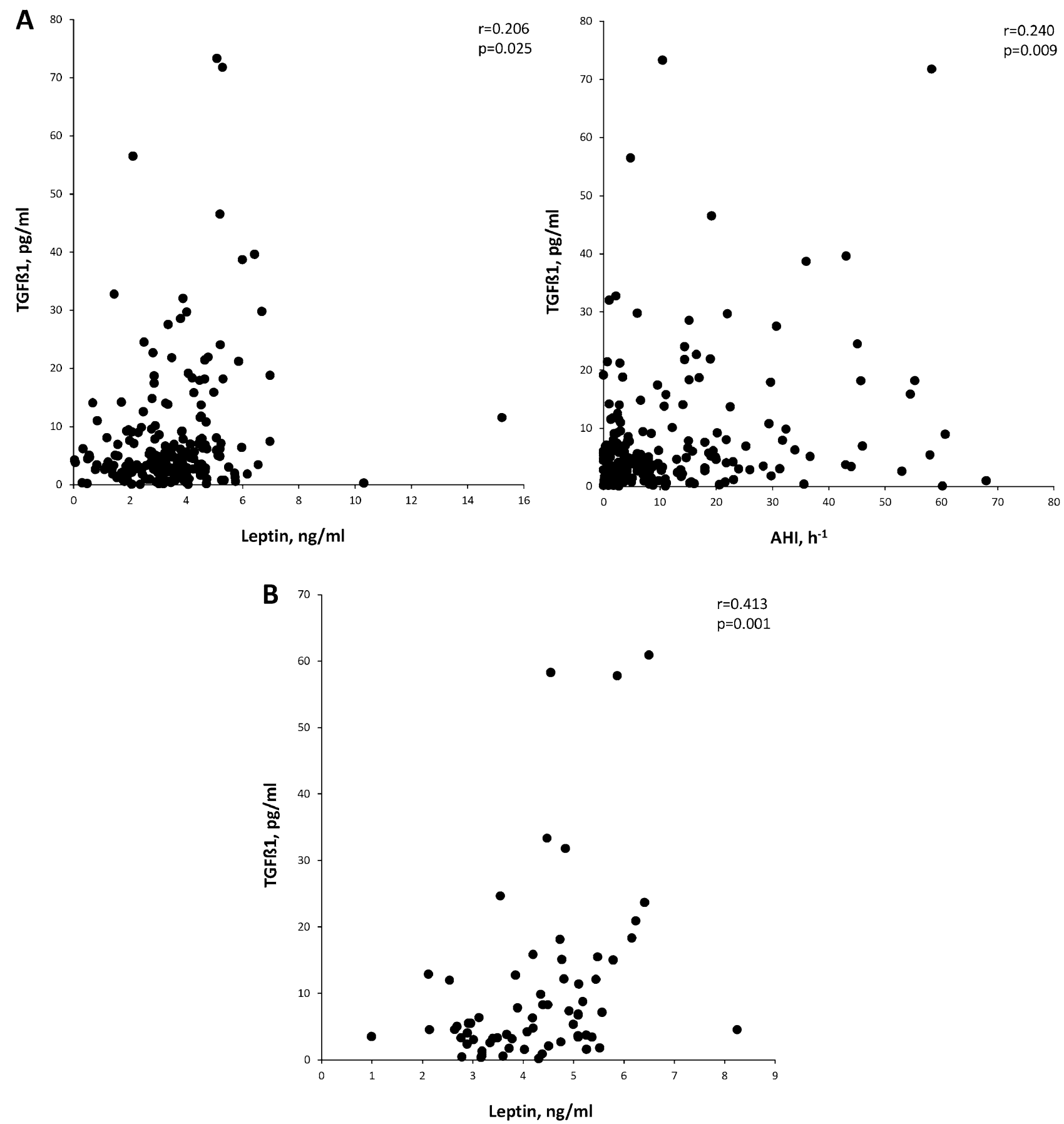

Figure 3. Independent factors related with serum levels of TGF- $\beta 1$ in non-obese (A) and obese (B) OSA patients.

our results suggest that the potential contribution of OSA to melanoma aggressiveness is limited to non-obese patients (Fig. 5). This finding concurs with the results from a murine subcutaneous melanoma model, in which the application of intermittent hypoxia mimicking OSA increased the growth of melanoma tumors in lean mice, but not in obese mice ${ }^{43}$. In fact, the increased tumor growth induced by obesity was not enhanced by adding the intermittent hypoxia stimulus, and the effect of intermittent hypoxia on tumor necrosis, and vascular density was dampened in the context of obesity ${ }^{43}$. Likewise, a previous analysis of the entire cohort of melanoma patients used in the present study showed that the probability of having a Breslow index $>1 \mathrm{~mm}$ in patients with an AHI or a desaturation index in the upper tertile compared with the reference group was higher in non-obese than in obese patients ${ }^{1}$. Although our results do not provide a mechanistic explanation for this finding, we speculate that the lack of a relationship between sleep parameters and active TGF- $\beta 1$ levels in obese patients with OSA might be attributable to the obesity-induced activation of the NFkB pathway, which could attenuate the OSA-induced HIF-1 $\alpha$-TGF- $\beta$ production pathway. On the other hand, we also cannot rule out competition for binding at 


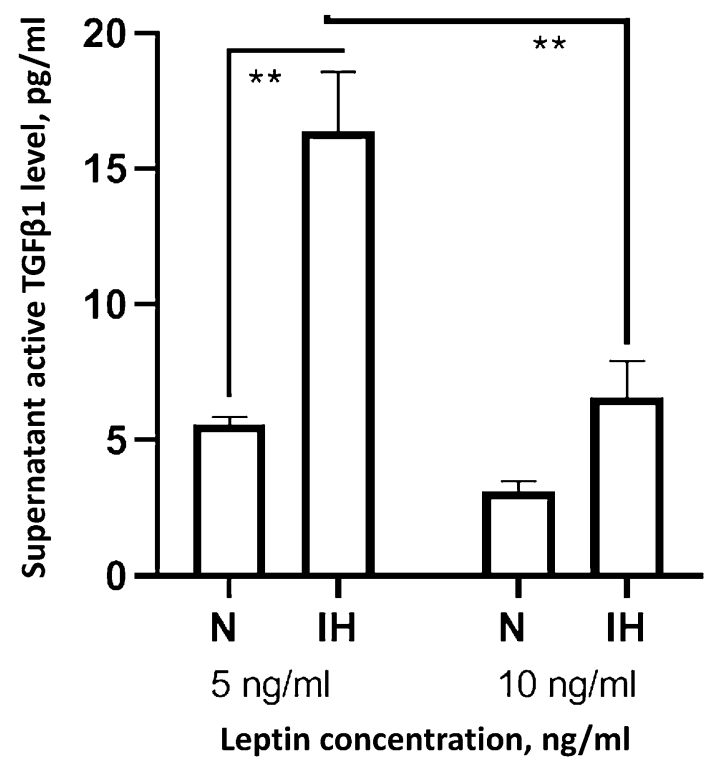

Figure 4. Supernatant levels of active TGF- $\beta 1$ in melanoma cells treated with human leptin protein concentration at $5 \mathrm{ng} \mathrm{mL}^{-1}$ or $10 \mathrm{ng} \mathrm{mL}^{-1}$ under normoxia or intermittent hypoxia conditions $(\mathrm{n}=7)$. Comparison of protein levels between groups was performed by one way ANOVA with multiple Turkey comparison. Error bars: SEM. ${ }^{* *} p<0.01$.

specific sites of the TGF- $\beta 1$ regulatory gene between transcription factors induced by the activation of the leptin receptor and by the increase of HIF-1 $\alpha$.

In addition to its multicenter character and the relatively large cohort size, as well as the homogenization and rigorous control of sleep studies performed by the Spanish Sleep Network, we believe that the main strength of this study was the measurement of free active TGF- $\beta 1$ in serum, which more reliably reflects effector activity of its several biological functions, such as activating epithelial mesenchymal transition, proliferation and the spread of metastasis ${ }^{44}$. However, our study has several limitations that must be acknowledged. First, the sleep study was performed using respiratory polygraphy rather than polysomnography, and it is therefore not possible to evaluate the contribution of sleep fragmentation. Second, there was a certain delay between the skin biopsy and polygraphic studies (which was not different between the study groups and never exceeded 4 months). Although no changes in patient weight or any other potential confounding factors were identified, we cannot rule out that such factors were void of any influence on our results. Third, as in most studies recruiting patients who had not been referred to sleep units for suspicion of OSA, daytime sleepiness in the OSA groups is low, which may be a limitation to extrapolate our findings to much more symptomatic patients. Fourth, we did not have a group of patients with distant metastatic melanoma to evaluate their serum TGF- $\beta 1$ and leptin levels. Fifth, our study does not provide any information on the effect of OSA treatment on TGF- $\beta 1$ levels or its effect on melanoma aggressiveness, and therefore no therapeutic recommendations beyond those in place for OSA can be formulated.

In summary, our study shows that melanoma patients with moderate-severe OSA have higher serum levels of active TGF- $\beta 1$, which are directly related to melanoma aggressiveness. Furthermore, in non-obese patients with OSA TGF- $\beta 1$ level variance is dependent on both AHI and serum leptin levels, while in obese patients with OSA only leptin levels retain their independent association with TGF- $\beta 1$ levels.

\section{Methods}

Study subjects. Adult patients with new diagnoses of cutaneous melanoma were consecutively selected from a multicenter, observational study involving 29 teaching hospitals in Spain ${ }^{1}$. Exclusion criteria included extra-cutaneous location of the melanoma, daytime respiratory or heart failure, and current or previous use of home oxygen therapy, continuous positive airway pressure (CPAP) or noninvasive mechanical ventilation. Out of 443 recruited patients, serum samples were obtained in 360 subjects and after their clinical use, were available in 290 patients. The study was approved by the Institutional Ethics Committee of the Hospital Universitario y Politécnico La Fe, Valencia, Spain (2016/0223), and all subjects gave their written informed consent. All the experiment protocol for involving humans was in accordance to Declaration of Helsinki.

Dermatological evaluation. As previously described ${ }^{45,46}$, patients were evaluated by a dermatologist at each hospital, and data for tumor location and clinical stage at diagnosis (categorized as localized or locoregional disease) were registered. All tumors were surgically removed, and the Breslow tumor thickness, ulceration, tumor mitotic rate, and Clark levels were calculated ${ }^{47}$. Melanoma growth rate was calculated as the Breslow index divided by the difference between the date of the tumor excision and the date on which patients noticed changes suggestive of malignant transformation in a stable, pre-existing lesion or the time when they noticed the 


\section{Leptin}

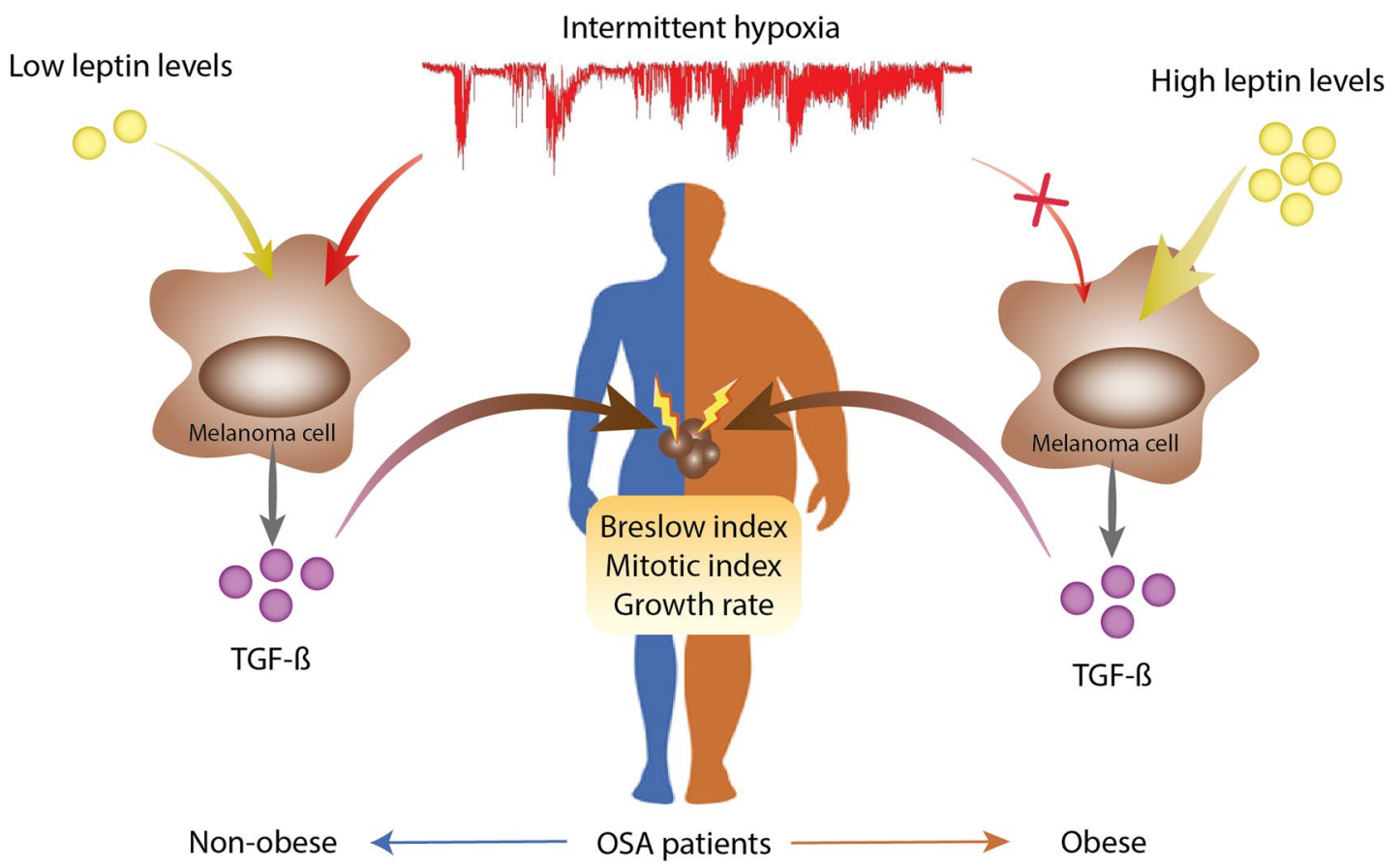

Figure 5. Schematic representation of the proposed interaction between intermittent hypoxia, obesity, and circulating levels of TGF- $B$ in patients with melanoma and OSA. In non-obese subjects, OSA-induced intermittent hypoxia could have a synergistic effect with leptin produced by adipocytes on the TGF- $ß$ expression by melanoma cells, promoting greater tumor aggressiveness. According to the data of the present study, this effect is lost in obese patients, since the basal overexpression of TGF- $B$ caused by high levels of leptin is not enhanced by the additional presence of intermittent hypoxia.

appearance of a new and changing lesion ${ }^{46}$. All dermatological and pathological evaluations were blinded to the sleep study and biochemical analysis findings.

Sleep study. Anthropometric characteristics were measured and, according to WHO criteria, obesity was defined as a body mass index (BMI) $\geq 30 \mathrm{~kg} \mathrm{~m}^{-2}$. Simultaneously, all patients underwent overnight respiratory polygraphy within a maximum of 4 months after CM diagnosis. All scoring and readings were conducted manually by experienced and trained personnel. Apnea was defined as an interruption of oronasal flow of $>10 \mathrm{~s}$. Hypopnea was defined as a 30-90\% reduction in the oronasal airflow for $>10 \mathrm{~s}$ associated with an oxygen desaturation $\geq 3 \%$. The apnea-hypopnea index (AHI) was defined as the number of apneas plus hypopneas per hour of recording, while tSat 90 was defined as the percentage of recording time with $\mathrm{SaO}_{2}<90 \%$. In addition, mean saturation, minimum saturation and oxygen desaturation index (ODI) were measured. According to the AHI, patients were divided into three groups: non-OSA (AHI 0-5 $\mathrm{h}^{-1}$ ), mild OSA (AHI 5-15 $\mathrm{h}^{-1}$ ) and moderatesevere OSA $\left(\mathrm{AHI}>15 \mathrm{~h}^{-1}\right)^{48}$.

Determination of serum levels of active TGF $\beta 1$ and leptin. Fasting venous blood samples were drawn between 8 and 9 am. The blood samples were centrifuged to separate the serum, and all specimens were immediately aliquoted, frozen and stored at $-80^{\circ} \mathrm{C}$. Free active TGF- $\beta 1$ and leptin in serum were assayed using human free active TGF- $\beta 1$ and leptin enzyme linked immunosorbent assay (437707 Legend Max, San Diego, USA and MBS9501873 MyBiosource, San Diego, USA, respectively) according to the manufacturers' instructions. The assays were done in duplicates in all samples. The detection limits of the assays were $63 \mathrm{pg} \mathrm{mL} \mathrm{m}^{-1}$ and $2.3 \mathrm{pg} \mathrm{mL}^{-1}$, respectively. The intra-assay and inter-assay variations were below $10 \%$ in all cases.

Cell culture. C81-61 human cutaneous melanoma cell line ${ }^{49}$ was cultured under normoxia or intermittent hypoxia $(\mathrm{IH})$ conditions over night, as previously described ${ }^{50}$. The culture medium was supplemented with human leptin (230-30112-10, RayBiotech) at either a concentration similar to that detected in patients or two- 
fold that level ( 5 and $10 \mathrm{ng} \mathrm{mL}^{-1}$, respectively). Supernatant concentrations of active TGF- $\beta 1$ were measured by ELISA as in serum.

RNA isolation, quantification, and analysis. Total RNA was purified using the High Pure RNA Isolation Kit (Ambion, Carlsbad, CA, USA). cDNA was obtained using the High Capacity cDNA Reverse Transcription Kit (Applied Biosystems). Gene expression levels were analyzed by real-time quantitative PCR using the LightCycler System (Roche Diagnostics, Basel Switzerland); and quantitative PCR was performed using a QuantiMix Easy SYG Kit (Biotools; Madrid, Spain). The results were normalized to the expression of 18S, and the cDNA copy number of each gene of interest was determined using a 7-point standard curve. The products were amplified using specific primers as described previously ${ }^{20}$. The products were amplified using primers for TGF- $\beta 1$ 5'-GGCCAGATCCTGTCCAAGC-3' (forward) and 5'- GTGGGTTTCCACCATTAGCAC-3' (reverse).

Statistical analysis. According the type and distribution of the variables, data are expressed as mean \pm SD, median (interquartile range $[\mathrm{IQR}]$ ) or absolute numbers and percentages. Normality was explored using the Shapiro-Wilk and skewness-kurtosis tests. Differences between groups were analyzed using the Chi-squared or Fisher's exact tests (categorical variables) and Kruskal-Wallis or Mann-Whitney U tests (ordinary or nonnormal metric variables). For between-group comparisons, TGF- $\beta 1$ and leptin levels were adjusted for gender, age, body mass index and neck circumference using general linear models. Correlations between parameters were evaluated using Spearman's correlation. Those variables exhibiting statistically significant findings were then introduced into a multiple linear regression analysis to identify independent determinants of TGF- $\beta 1$ levels. Stepwise methods were used to include or remove individual independent variables at each step, based on the probability of $\mathrm{F}$ (entry: 0.05 ; removal: 0.10 ). Other aspects explored included residual standard deviation, changes in the distribution of the residuals and the homogeneity of the variance over the predictors ${ }^{51}$. Analyses were performed using the Statistical Package for the Social Sciences (version 20.0; SPSS, Chicago, IL, USA).

Received: 18 May 2020; Accepted: 9 July 2020

Published online: 23 September 2020

\section{References}

1. Martinez-Garcia, M. A. et al. Sleep-disordered breathing is independently associated with increased aggressiveness of cutaneous melanoma: a multicenter observational study in 443 patients. Chest 154, 1348-1358. https://doi.org/10.1016/j.chest.2018.07.015 (2018).

2. Martinez-Garcia, M. A. et al. Cancer and sleep apnea: cutaneous melanoma as a case study. Am. J. Respir. Crit. Care. Med. https:// doi.org/10.1164/rccm.201903-0577PP (2019).

3. Almendros, I. et al. Intermittent hypoxia-induced changes in tumor-associated macrophages and tumor malignancy in a mouse model of sleep apnea. Am. J. Respir. Crit. Care. Med. 189, 593-601. https://doi.org/10.1164/rccm.201310-1830OC (2014).

4. Cubillos-Zapata, C. et al. Hypoxia-induced PD-L1/PD-1 crosstalk impairs T-cell function in sleep apnoea. Eur. Respir. J. https:// doi.org/10.1183/13993003.00833-2017 (2017).

5. Cubillos-Zapata, C. et al. Soluble PD-L1 is a potential biomarker of cutaneous melanoma aggressiveness and metastasis in obstructive sleep apnoea patients. Eur. Respir. J. https://doi.org/10.1183/13993003.01298-2018 (2019).

6. Javelaud, D., Alexaki, V. I. \& Mauviel, A. Transforming growth factor-beta in cutaneous melanoma. Pigment Cell Melanoma Res. 21, 123-132. https://doi.org/10.1111/j.1755-148X.2008.00450.x (2008).

7. Massague, J. TGFbeta signalling in context. Nat. Rev. Mol. Cell. Biol. 13, 616-630. https://doi.org/10.1038/nrm3434 (2012).

8. Moustakas, A., Pardali, K., Gaal, A. \& Heldin, C. H. Mechanisms of TGF-beta signaling in regulation of cell growth and differentiation. Immunol. Lett. 82, 85-91. https://doi.org/10.1016/s0165-2478(02)00023-8 (2002).

9. Pennison, M. \& Pasche, B. Targeting transforming growth factor-beta signaling. Curr. Opin. Oncol. 19, 579-585. https://doi. org/10.1097/CCO.0b013e3282f0ad0e (2007).

10. Khan, S. A., Joyce, J. \& Tsuda, T. Quantification of active and total transforming growth factor-beta levels in serum and solid organ tissues by bioassay. BMC Res. Notes 5, 636. https://doi.org/10.1186/1756-0500-5-636 (2012).

11. Schlegel, N. C., von Planta, A., Widmer, D. S., Dummer, R. \& Christofori, G. PI3K signalling is required for a TGFbeta-induced epithelial-mesenchymal-like transition (EMT-like) in human melanoma cells. Exp. Dermatol. 24, 22-28. https://doi.org/10.1111/ exd.12580 (2015).

12. Mohammad, K. S. et al. TGF-beta-RI kinase inhibitor SD-208 reduces the development and progression of melanoma bone metastases. Cancer Res. 71, 175-184. https://doi.org/10.1158/0008-5472.can-10-2651 (2011).

13. Tas, F., Karabulut, S., Yasasever, C. T. \& Duranyildiz, D. Serum transforming growth factor-beta 1 (TGF-beta1) levels have diagnostic, predictive, and possible prognostic roles in patients with melanoma. Tumour Biol. 35, 7233-7237. https://doi.org/10.1007/ s13277-014-1984-z (2014).

14. Tuncer, E. et al. SMAD signaling promotes melanoma metastasis independently of phenotype switching. J. Clin. Investig. 129, 2702-2716. https://doi.org/10.1172/jci94295 (2019).

15. Yang, Y. A. et al. Lifetime exposure to a soluble TGF-beta antagonist protects mice against metastasis without adverse side effects. J. Clin. Investig. 109, 1607-1615. https://doi.org/10.1172/jci15333 (2002).

16. Morita, T. \& Hayashi, K. Tumor progression is mediated by thymosin-beta4 through a TGFbeta/MRTF signaling axis. Mol. Cancer Res. 16, 880-893. https://doi.org/10.1158/1541-7786.mcr-17-0715 (2018).

17. Yoshimoto, S., Tanaka, F., Morita, H., Hiraki, A. \& Hashimoto, S. Hypoxia-induced HIF-1alpha and ZEB1 are critical for the malignant transformation of ameloblastoma via TGF-beta-dependent EMT. Cancer Med https://doi.org/10.1002/cam4.2667 (2019).

18. Han, W. Q. et al. Hypoxia-inducible factor prolyl-hydroxylase-2 mediates transforming growth factor beta 1-induced epithelial-mesenchymal transition in renal tubular cells. Biochim. Biophys. Acta 1454-1462, 2013. https://doi.org/10.1016/j.bbamc r.2013.02.029 (1833).

19. Zhao, B. et al. Hypoxia drives the transition of human dermal fibroblasts to a myofibroblast-like phenotype via the TGF-betal/ Smad3 pathway. Int. J. Mol. Med. 39, 153-159. https://doi.org/10.3892/ijmm.2016.2816 (2017).

20. Hernandez-Jimenez, E. et al. Monocytes inhibit NK activity via TGF-beta in patients with obstructive sleep apnoea. Eur. Respir. J. https://doi.org/10.1183/13993003.02456-2016 (2017). 
21. Mishra, A. K., Parish, C. R., Wong, M. L., Licinio, J. \& Blackburn, A. C. Leptin signals via TGFB1 to promote metastatic potential and stemness in breast cancer. PLoS ONE 12, e0178454. https://doi.org/10.1371/journal.pone.0178454 (2017).

22. Mingyuan, X. et al. Hypoxia-inducible factor-1alpha activates transforming growth factor-beta1/Smad signaling and increases collagen deposition in dermal fibroblasts. Oncotarget 9, 3188-3197. https://doi.org/10.18632/oncotarget.23225 (2018).

23. Lei, R. et al. HIF-1alpha promotes the keloid development through the activation of TGF-beta/Smad and TLR4/MyD88/NF-kappaB pathways. Cell Cycle https://doi.org/10.1080/15384101.2019.1670508 (2019).

24. Colak, S. \& Ten Dijke, P. Targeting TGF-beta signaling in cancer. Trends Cancer 3, 56-71. https://doi.org/10.1016/j.treca n.2016.11.008 (2017).

25. von Gersdorff, G. et al. Smad3 and Smad4 mediate transcriptional activation of the human Smad7 promoter by transforming growth factor beta. J. Biol. Chem. 275, 11320-11326. https://doi.org/10.1074/jbc.275.15.11320 (2000).

26. Deng, B. et al. Intratumor hypoxia promotes immune tolerance by inducing regulatory T cells via TGF-betal in gastric cancer. PLoS ONE 8, e63777. https://doi.org/10.1371/journal.pone.0063777 (2013).

27. Dumaine, J. E. \& Ashley, N. T. Acute sleep fragmentation induces tissue-specific changes in cytokine gene expression and increases serum corticosterone concentration. Am. J. Physiol. Regul. Integr. Comp. Physiol. 308, R1062-1069. https://doi.org/10.1152/ajpre gu.00049.2015 (2015).

28. Ungefroren, H., Gieseler, F., Fliedner, S. \& Lehnert, H. Obesity and cancer. Hormone Mol. Biol. Clin. Investig. 21, 5-15. https://doi. org/10.1515/hmbci-2014-0046 (2015).

29. Vaisse, C. et al. Leptin activation of Stat3 in the hypothalamus of wild-type and ob/ob mice but not db/db mice. Nat. Genet. 14, 95-97. https://doi.org/10.1038/ng0996-95 (1996).

30. Park, J., Kusminski, C. M., Chua, S. C. \& Scherer, P. E. Leptin receptor signaling supports cancer cell metabolism through suppression of mitochondrial respiration in vivo. Am. J. Pathol. 177, 3133-3144. https://doi.org/10.2353/ajpath.2010.100595 (2010).

31. Fan, Y. et al. Leptin signaling enhances cell invasion and promotes the metastasis of human pancreatic cancer via increasing MMP13 production. Oncotarget 6, 16120-16134. https://doi.org/10.18632/oncotarget.3878 (2015).

32. Kumpers, P. et al. Leptin is a coactivator of TGF-beta in unilateral ureteral obstructive kidney disease. Am. J. Physiol. Renal Physiol. 293, F1355-1362. https://doi.org/10.1152/ajprenal.00003.2007 (2007).

33. Wada, N. et al. Leptin and its receptors. J. Chem. Neuroanat. 61-62, 191-199. https://doi.org/10.1016/j.jchemneu.2014.09.002 (2014).

34. Yadav, H. et al. Protection from obesity and diabetes by blockade of TGF-beta/Smad3 signaling. Cell Metab. 14, 67-79. https://doi. org/10.1016/j.cmet.2011.04.013 (2011).

35. Tan, C. K. et al. Smad3 deficiency in mice protects against insulin resistance and obesity induced by a high-fat diet. Diabetes 60, 464-476. https://doi.org/10.2337/db10-0801 (2011).

36. de Caestecker, M. The transforming growth factor-beta superfamily of receptors. Cytokine Growth Factor Rev. 15, 1-11 (2004).

37. Almendros, I., Martínez-García, M. A., Farre, R. \& Gozal, D. Obesity, sleep apnea and cancer. Int. J. Obes. 44, 1653-1667 (2020).

38. Calle, E. E., Rodriguez, C., Walker-Thurmond, K. \& Thun, M. J. Overweight, obesity, and mortality from cancer in a prospectively studied cohort of U.S. adults. N. Engl. J. Med. 348, 1625-1638. https://doi.org/10.1056/NEJMoa021423 (2003).

39. Wolin, K. Y., Carson, K. \& Colditz, G. A. Obesity and cancer. Oncologist 15, 556-565. https://doi.org/10.1634/theoncologist.20090285 (2010).

40. Mori, A. et al. Severe pulmonary metastasis in obese and diabetic mice. Int. J. Cancer 119, 2760-2767. https://doi.org/10.1002/ ijc.22248 (2006).

41. Ackerman, S. E., Blackburn, O. A., Marchildon, F. \& Cohen, P. Insights into the link between obesity and cancer. Curr. Obes. Rep. 6, 195-203. https://doi.org/10.1007/s13679-017-0263-x (2017).

42. Jones, D. H., Nestore, M., Henophy, S., Cousin, J. \& Comtois, A. S. Increased cardiovascular risk factors in breast cancer survivors identified by routine measurements of body composition, resting heart rate and arterial blood pressure. SpringerPlus 3,150 . https ://doi.org/10.1186/2193-1801-3-150 (2014).

43. Almendros, I. et al. Obesity and intermittent hypoxia increase tumor growth in a mouse model of sleep apnea. Sleep Med. 13, 1254-1260. https://doi.org/10.1016/j.sleep.2012.08.012 (2012).

44. Liu, S., Chen, S. \& Zeng, J. TGFbeta signaling: a complex role in tumorigenesis (Review). Mol. Med. Rep. 17, 699-704. https://doi. org/10.3892/mmr.2017.7970 (2018).

45. Martinez-Garcia, M. A. et al. A prospective multicenter cohort study of cutaneous melanoma: clinical staging and potential associations with HIF-1alpha and VEGF expressions. Melanoma Res. 27, 558-564. https://doi.org/10.1097/cmr.0000000000000393 (2017).

46. Martinez-Garcia, M. A. et al. Association between sleep disordered breathing and aggressiveness markers of malignant cutaneous melanoma. Eur. Respir. J. 43, 1661-1668. https://doi.org/10.1183/09031936.00115413 (2014).

47. Gershenwald, J. E. et al. Melanoma staging: evidence-based changes in the American Joint Committee on Cancer eighth edition staging manual. CA Cancer J Clin 67, 472-492. https://doi.org/10.3322/caac.21409 (2017).

48. Lloberes, P. et al. Diagnosis and treatment of sleep apnea-hypopnea syndrome. Spanish Society of Pulmonology and Thoracic Surgery. Arch. Bronconeumol. 47, 143-156. https://doi.org/10.1016/j.arbres.2011.01.001 (2011).

49. Itzhaki, O. et al. Nicotinamide inhibits vasculogenic mimicry, an alternative vascularization pathway observed in highly aggressive melanoma. PLoS ONE 8, e57160. https://doi.org/10.1371/journal.pone.0057160 (2013).

50. Cubillos-Zapata, C. et al. Differential effect of intermittent hypoxia and sleep fragmentation on PD-1/PD-L1 upregulation. Sleep https://doi.org/10.1093/sleep/zsz285 (2019).

51. Krzywinski, M. \& Altman, N. Multiple linear regression. Nat. Methods 12, 1103-1104. https://doi.org/10.1038/nmeth.3665 (2015).

\section{Acknowledgements}

This study was supported by Grants from Fondo de Investigación Sanitaria (FIS) and Fondos FEDER PI16/00201 and PI19/01612 to F. García-Río, PI19/01363 to C. Cubillos-Zapata and PIE15/00065 to E. López-Collazo. M.A. Martínez-García is supported by the Spanish Ministry of Economy and Competitiveness-Instituto de Salud Carlos III (FIS 2016/ 01772) and co-financed by the European Development Regional Fund. A way to achieve Europe (ERDF). DG is supported in part by National Institutes of Health grants HL130984 and HL140548. The sponsors had no role in the design of the study, the collection and analysis of the data, or the preparation of the manuscript.

\section{Author contributions}

C.C.Z., M.A.M.G., D.G. and F.G.R. designed research; C.C.Z., E.D.G., A.J., F.C.R., M.S.T., E.N., A.M.C., L.H.B., E.P., J.A.C., J.M.M., V.C.N., I.C.P., J.C.P., E.A., O.M., M.S.G., J.D.A., I.A., R.F., E.L.C., D.G. and F.G.R. performed research; C.C.Z., E.D.G. and A.J. contributed new reagents or analytic tools; C.C.Z. and F.G.R. analyzed data; C.C.Z. and F.G.R. wrote the paper. 


\section{Competing interests}

The authors declare no competing interests.

\section{Additional information}

Supplementary information is available for this paper at https://doi.org/10.1038/s41598-020-72481-x.

Correspondence and requests for materials should be addressed to F.G.-R.

Reprints and permissions information is available at www.nature.com/reprints.

Publisher's note Springer Nature remains neutral with regard to jurisdictional claims in published maps and institutional affiliations.

Open Access This article is licensed under a Creative Commons Attribution 4.0 International (c) License, which permits use, sharing, adaptation, distribution and reproduction in any medium or format, as long as you give appropriate credit to the original author(s) and the source, provide a link to the Creative Commons licence, and indicate if changes were made. The images or other third party material in this article are included in the article's Creative Commons licence, unless indicated otherwise in a credit line to the material. If material is not included in the article's Creative Commons licence and your intended use is not permitted by statutory regulation or exceeds the permitted use, you will need to obtain permission directly from the copyright holder. To view a copy of this licence, visit http://creativecommons.org/licenses/by/4.0/.

(c) The Author(s) 2020 